\title{
The long road to automation: neurocognitive development of letter-speech sound processing
}

Citation for published version (APA):

Froyen, D. J. W., Bonte, M. L., van Atteveldt, N. M., \& Blomert, L. (2009). The long road to automation: neurocognitive development of letter-speech sound processing. Journal of Cognitive Neuroscience, 21(3), 567-580. https://doi.org/10.1162/jocn.2009.21061

Document status and date:

Published: 01/01/2009

DOI:

10.1162/jocn.2009.21061

Document Version:

Publisher's PDF, also known as Version of record

Document license:

Taverne

Please check the document version of this publication:

- A submitted manuscript is the version of the article upon submission and before peer-review. There can be important differences between the submitted version and the official published version of record.

People interested in the research are advised to contact the author for the final version of the publication, or visit the DOI to the publisher's website.

- The final author version and the galley proof are versions of the publication after peer review.

- The final published version features the final layout of the paper including the volume, issue and page numbers.

Link to publication

\footnotetext{
General rights rights.

- You may freely distribute the URL identifying the publication in the public portal. please follow below link for the End User Agreement:

www.umlib.nl/taverne-license

Take down policy

If you believe that this document breaches copyright please contact us at:

repository@maastrichtuniversity.nl

providing details and we will investigate your claim.
}

Copyright and moral rights for the publications made accessible in the public portal are retained by the authors and/or other copyright owners and it is a condition of accessing publications that users recognise and abide by the legal requirements associated with these

- Users may download and print one copy of any publication from the public portal for the purpose of private study or research.

- You may not further distribute the material or use it for any profit-making activity or commercial gain

If the publication is distributed under the terms of Article $25 \mathrm{fa}$ of the Dutch Copyright Act, indicated by the "Taverne" license above, 
See discussions, stats, and author profiles for this publication at: https://www.researchgate.net/publication/5258679

\section{The Long Road to Automation: Neurocognitive Development of Letter-Speech Sound Processing}

Article in Journal of Cognitive Neuroscience · August 2008

DOI: 10.1162/jocn.2009.21061 · Source: PubMed

CITATIONS

141

4 authors:

Dries Froyen

Vlaams Ministerie van Onderwijs en Vorming

8 PUBLICATIONS 431 CITATIONS

SEE PROFILE

3

Nienke van Atteveldt

Vrije Universiteit Amsterdam

67 PUBLICATIONS 2,655 CITATIONS

SEE PROFILE

Some of the authors of this publication are also working on these related projects:

Project Developmental and task-dependent plasticity in speech perception View project

Project Dyslexia and the brain View project
READS

153

Milene Bonte

Maastricht University

86 PUBLICATIONS 2,337 CITATIONS

SEE PROFILE

Leo Blomert

Maastricht University

71 PUBLICATIONS 4,974 CITATIONS

SEE PROFILE 


\title{
The Long Road to Automation: Neurocognitive Development of Letter-Speech Sound Processing
}

\author{
Dries J. W. Froyen, Milene L. Bonte, Nienke van Atteveldt, \\ and Leo Blomert
}

\begin{abstract}
In transparent alphabetic languages, the expected standard for complete acquisition of letter-speech sound associations is within one year of reading instruction. The neural mechanisms underlying the acquisition of letter-speech sound associations have, however, hardly been investigated. The present article describes an ERP study with beginner and advanced readers in which the influence of letters on speech sound processing is investigated by comparing the MMN to speech sounds presented in isolation with the MMN to speech sounds accompanied by letters. Furthermore, SOA between letter and speech sound presentation was manipulated in order to investigate the development of the temporal window of integration for letter-speech sound processing. Beginner readers, despite one year of reading instruction, showed no early
\end{abstract}

\section{INTRODUCTION}

The acquisition of letter-speech sound associations is considered the basic requirement for learning to read (Ehri, 2005; Frith, 1985). Additionally, it is suggested that deficient letter-speech sound association forms the basis for the difficulties in learning to read in developmental dyslexia (Vellutino, Fletcher, Snowling, \& Scanlon, 2004; Fox, 1994; Frith, 1985; Snowling, 1980). A better understanding of the development of this association process will provide insights in the cognitive requirements for learning to read and will contribute to the research of reading disabilities such as developmental dyslexia.

Because written language is a relatively recent cultural invention, an evolutionarily adapted brain mechanism for processing script most likely does not exist. Moreover, in contrast with the natural association between auditory and visual information in, for example, audiovisual speech (Calvert, Brammer, \& Iversen, 1998), the association between letters and speech sounds is basically arbitrary in nature. It is therefore remarkable that literacy skills are so easily acquired in most languages. In

University of Maastricht letter-speech sound integration, that is, no influence of the letter on the evocation of the MMN to the speech sound. Only later in the difference wave, at $650 \mathrm{msec}$, was an influence of the letter on speech sound processing revealed. Advanced readers, with 4 years of reading instruction, showed early and automatic letter-speech sound processing as revealed by an enhancement of the MMN amplitude, however, at a different temporal window of integration in comparison with experienced adult readers. The present results indicate a transition from mere association in beginner readers to more automatic, but still not "adult-like," integration in advanced readers. In contrast to general assumptions, the present study provides evidence for an extended development of letter-speech sound integration. a relatively transparent language like Dutch, in which the letter-speech sound associations are mostly unambiguous, the expected educational standard for complete mastery of letter-speech sound associations is within one year of reading instruction (Wentink \& Verhoeven, 2003). Even in English, an opaque language regarding the associations between orthography and phonology, letter-speech sound associations seem to be established within a few years of reading instruction (Siegel \& Faux, 1989; Snowling, 1980; Hardy, Smythe, Stennet, \& Wilson, 1972). In a study in which children had to decide whether single letters matched with single speech sounds, most letter-speech sound associations were judged correctly by at least $80 \%$ of all children within one year of reading instruction (Hardy et al., 1972).

The seemingly easy acquisition of letter-speech sound associations needs, however, closer examination as recent data indicate that knowing the associations between letters and speech sounds might not be the same as the instrumental use of this association in learning to read. In a study on a large nationwide sample of Dutch primary school children from 6 to 12 years old, not only accuracy but also reaction time data on letter-speech sound association were collected (Blomert \& Vaessen, in press). 
Surprisingly, in light of the expected mastery of letterspeech sound associations within one year of reading instruction, reaction times of letter-speech sound discrimination decisions steadily decreased during the whole range of Dutch primary school reading instruction. Because faster processing is one of the main criteria for the automation of a process (Schneider \& Chein, 2003), the extended decrease of processing time for letter-speech sound discrimination might indicate an extended development towards automatic letter-speech sound association. Although early acquisition of letter-speech sound associations is generally assumed in transparent languages, exactly when and how these associations develop in the human brain remains an open question, and is the topic of the present article.

One of the first indications about the nature of fully developed letter-speech sound processing came from an early behavioral study showing differential influences of congruent and incongruent letter primes on reaction times in a speech sound identification task (Dijkstra, Schreuder, \& Frauenfelder, 1989). More recently, in a brain imaging study using MEG, integration of letters and speech sounds was reported in the superior temporal sulcus (STS) (Raij, Uutela, \& Hari, 2000). Moreover, two fMRI studies revealed that not only heteromodal regions in the STS and the superior temporal gyrus (STG) but also the unimodal auditory association cortex (planum temporale, PT) is involved in the letter-speech sound integration process (Van Atteveldt, Formisano, Blomert, \& Goebel, 2007; Van Atteveldt, Formisano, Goebel, \& Blomert, 2004). The involvement of the auditory cortex for letter-speech sound integration was recently confirmed in an MEG study (Herdman et al., 2006). Given the passive nature of the tasks used in both fMRI studies (passive viewing/listening), letterspeech sound integration was suggested to occur automatically. Van Atteveldt et al. (2007) furthermore manipulated the SOA between the presentation of the letter and the speech sound. Manipulating the SOA revealed a narrow temporal window for integration of letters with speech sounds in the PT. Integration, as reflected by response enhancement for congruent and suppression for incongruent letter-speech sound pairs (relative to the maximal unimodal response), was maximal at simultaneous presentation of letters with speech sounds and had already declined at $150 \mathrm{msec}$ SOA (Van Atteveldt et al., 2007). To summarize, current evidence indicates that fully developed letter-speech sound processing in adults is achieved through automatic integration performed by a network located in the PT and the STS/STG, where the multisensory effect in PT only occurs within a narrow temporal window under the condition that letters and speech sounds are presented simultaneously.

These recent insights into the brain mechanisms involved in fully automated letter-speech sound processing open new perspectives for the investigation of its development. Knowing the associations between letters and speech sounds is apparently only in the starting point of the development toward automatic letter-speech sound integration. In the present study, we therefore further investigated when and how letter-speech sound processing develops by means of ERPs, known for its high temporal resolution. In a recent ERP study, the MMN was successfully used to investigate the automation and timing properties of letter-speech sound integration in experienced adult readers (Froyen, Van Atteveldt, Bonte, \& Blomert, 2008). The MMN is known to be evoked automatically between 100 and $200 \mathrm{msec}$ when, in a sequence of auditory stimuli, a rarely presented sound (the deviant) deviates in one or more aspects from the sound that is frequently presented (the standard) (Näätänen, Paavilainen, Tiitinen, Jiang, \& Alho, 1993). The MMN is considered to reflect the neurophysiological correlate of a comparison process between an incoming auditory stimulus and the memory trace formed by the repetitive aspect of the standard stimulus (Näätänen, 2000; Picton, Alain, Otten, Ritter, \& Achim, 2000; Schröger, 1998). The MMN has repeatedly been shown to be sensitive to language-specific speech sound representations in adults and in children (Bonte, Poelmans, \& Blomert, 2007; Mitterer \& Blomert, 2003; Näätänen, 2001; Winkler et al., 1999). The child MMN is furthermore suggested to be a stable component resembling the adult MMN (Csépe, 2003). The MMN is particularly interesting and useful for research with children because its evocation does not require sustained attention.

In an MMN study with experienced adult readers, the MMN evoked by the deviant speech sound violating the standard speech sound (Figure 1A) was compared with the MMN evoked by the deviant speech sound violating both the standard speech sound and the corresponding letter (Figure 1B) (Froyen et al., 2008). The results re-

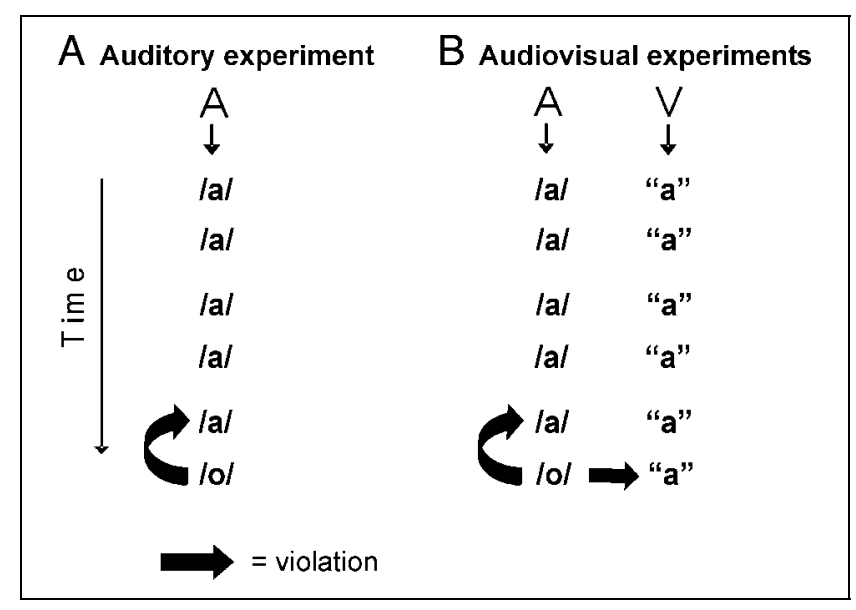

Figure 1. Designs of the auditory experiment (A) and the audiovisual experiment (B). "A" represents auditory stimulus presentation, "V" represents visual stimulus presentation. The arrow indicates the violation of the standard speech sound in the auditory experiment (A) and the violation of both the standard speech sound and the letter in the audiovisual experiment (AV). 
vealed a clear enhancement of the MMN amplitude evoked in the audiovisual experiment in comparison with the MMN amplitude in the auditory experiment. Considering the properties of the MMN, this enhancement strongly points to automatic integration of letters and speech sounds. Froyen et al. (2008) also manipulated the SOA between the presentation of the letter and the speech sound. Only when the letter was presented simultaneously with the speech sound did the letter have an influence on the processing of the speech sound, while at $100 \mathrm{msec}$ SOA the influence of the letter diminished significantly. The consistent SOA effect found with different methods, ERP (Froyen et al., 2008) and fMRI (Van Atteveldt et al., 2007), strongly points to temporal proximity as a critical factor for automatic letterspeech sound integration.

Because the present study aims at determining when and how letter-speech sound integration develops, we used the same design and ERP measurement with beginner and advanced readers as used in the study with adult readers (Froyen et al., 2008). In order to investigate the development of the temporal window for integration, we included two different SOAs; letters and speech sounds were presented simultaneously or with an SOA of $200 \mathrm{msec}$. The temporal integration window describes the time span within which two physically separated events are perceived as appearing together (Van Wassenhove, Grant, \& Poeppel, 2007; Yabe et al., 1998, 2004). To our knowledge, there are no studies investigating the development of the temporal integration window in letter-speech sound perception. There is, however, some evidence that children between 8 and 12 years of age perceive an auditory and a visual stimulus as occurring simultaneously in a wider temporal window than adults do (Laasonen, Service, \& Virsu, 2002; Laasonen, Tomma-Halme, Lahti-Nuuttila, Service, $\&$ Virsu, 2000). To provide insight into the dynamics of the development of letter-speech sound associations, we investigated the temporal window of integration for letter-speech sound processing in two different age groups in whom letter-speech sound processing might still be developing. We included two SOAs in the present study, the SOA for which the adults revealed maximal integration and the SOA for which we found no integration at all (Froyen et al., 2008).

First, we hypothesized that a typical MMN would be elicited to the speech sounds in both beginner (1 year of reading instruction) and advanced readers (4 years of reading instruction). Second, as the educational standard for fully mastering letter-speech sound associations is expected to be reached within one year of reading instruction (Wentink \& Verhoeven, 2003), we predicted an influence of the letter on the MMN evoked to a speech sound in both age groups. Third, the decreasing reaction time for letter-speech sound associations over the whole primary school range (Blomert \& Vaessen, in press) may be reflected in an MMN latency difference between beginner and advanced readers. This would be in line with previously reported decreasing MMN response latencies over development (Bonte et al., 2007; Maurer, Bucher, Brem, \& Brandeis, 2003; Shafer, Morr, Kreuzer, \& Kurtzberg, 2000). Finally, "adult-like" letter-speech sound integration is achieved within a narrow temporal window of integration, that is, only if stimuli are presented simultaneously (Froyen et al., 2008; Van Atteveldt et al., 2007). The results from Laasonen et al. (2000, 2002) suggest that we might expect a wider temporal window for letter-speech sound processing for advanced readers (11 years old) than for experienced adult readers (Froyen et al., 2008; Van Atteveldt et al., 2007). This might be reflected in appropriate integration at $200 \mathrm{msec}$ SOA and $0 \mathrm{msec}$ SOA for beginner and advanced readers, whereas adults only integrate at $0 \mathrm{msec}$ SOA (Froyen et al., 2008; Van Atteveldt et al., 2007).

\section{METHODS}

\section{Subjects}

Sixty-four normally reading subjects participated in the present study. To investigate developmental effects of letter-speech sound associations, two age groups were created. Thirty-eight subjects were recruited from Grade 2, having received one year of reading instruction. Thirteen subjects participated in the auditory experiment ( 3 girls, range [years; months] $=7 ; 01$ to $8 ; 10$ years, mean age $=$ $7 ; 08$ years), 14 subjects participated in the audiovisual experiment with 0 msec SOA ( 8 girls, range $=7 ; 06$ to 9 years, mean age $=8 ; 02$ years), and 17 subjects participated in the audiovisual experiment with $200 \mathrm{msec}$ SOA $(7$ girls, range $=6 ; 11$ to 9 years, mean age $=$ 7;06 years). Six subjects participated in two experiments, the auditory experiment and the audiovisual experiment with $0 \mathrm{msec}$ SOA. Data of two subjects in the audiovisual experiment with $200 \mathrm{msec}$ SOA were discarded due to excessive movement artifacts. Twenty-six subjects were recruited from Grade 5, having received 4 years of reading instruction. Twelve subjects participated in the auditory experiment ( 3 girls, range $=10 ; 06$ to $12 ; 09$ years, mean age $=11 ; 04$ years $), 13$ subjects participated in the audiovisual experiment with $0 \mathrm{msec}$ SOA $(9$ girls, range $=10$ to $12 ; 09$ years, mean age $=11 ; 02$ years), and 14 subjects participated in the audiovisual experiments with $200 \mathrm{msec}$ SOA $(7$ girls, range $=10 ; 02$ to $11 ; 08$ years, mean age $=$ $11 ; 01$ years). Seven subjects participated in both the auditory experiment and the audiovisual experiment with 0 msec SOA, whereas four subjects participated in the auditory experiment and the audiovisual experiment with $200 \mathrm{msec}$ SOA. Data of three subjects (one in the audiovisual experiment with 0 msec SOA and two in the audiovisual experiment with $200 \mathrm{msec}$ SOA) were discarded due to excessive movement artifacts.

All children were given a present for participation. Informed consent was obtained from the children and 
the parents. Approval for the study was granted by the Ethical Committee of the Faculty of Psychology at the University of Maastricht. The children were recruited from local schools in The Netherlands, and were judged by their school teachers to be average or above average in school achievement. All subjects were native Dutch speakers. Subject results of behavioral tests are summarized in Table 1. IQ assessment was established with the Raven Colored Progressive Matrices (Raven, Raven, \& Court, 1998). All children performed standardized language tests, the Eén-minuut-leestest (Brus \& Voeten, 1973) and a nonword reading test (Van den Bos, Lutje Spelberg, Scheepsma, \& De Vries, 1999). Results of the behavioral tests showed no differences in IQ, word reading, or phonological decoding (nonword reading) between the groups of the same age participating in the different experiments (Table 1).

\section{Stimuli}

Stimuli were speech sounds, /a/ (384 msec) and /o/ (348 $\mathrm{msec})$, and the visually presented single letter "a." We used the same stimuli as used in the adult study (Froyen et al., 2008), the same vowels as used in an MMN study on gender differences in speech and nonspeech processing (Kasai et al., 2002). To ensure a typical MMN reflecting speech sound processing, we used natural vowels (Näätänen, 2001). Furthermore, we chose the vowels "o" and "a" as these are completely transparent in their letter-speech sound correspondence

Table 1. Descriptive Data (Mean and Standard Deviation) for the Two Age Groups in Each Experiment

\begin{tabular}{|c|c|c|c|c|}
\hline & $A$ & $\begin{array}{c}A V \\
0 \text { msec }\end{array}$ & $\begin{array}{c}A V \\
200 \mathrm{msec}\end{array}$ & Differences \\
\hline \multicolumn{5}{|c|}{ Beginner Readers } \\
\hline $\begin{array}{l}\text { Word } \\
\quad \text { reading }\end{array}$ & $12.8(2.0)$ & $13.9(1.5)$ & $12.5(2.4)$ & $p=.228$ \\
\hline $\begin{array}{l}\text { Nonword } \\
\text { reading }^{\mathrm{a}}\end{array}$ & $12.6(1.7)$ & $14.5(2.2)$ & $12.5(2.0)$ & $p=.066$ \\
\hline Ravens SS ${ }^{\mathrm{b}}$ & $7.2(1.5)$ & $6.9(1.8)$ & $6.5(1.7)$ & $p=.421$ \\
\hline \multicolumn{5}{|c|}{ Advanced Readers } \\
\hline $\begin{array}{l}\text { Word } \\
\text { reading }^{\mathrm{a}}\end{array}$ & $13.1(1.8)$ & $13.1(2.4)$ & $12(1.4)$ & $p=.307$ \\
\hline $\begin{array}{l}\text { Nonword } \\
\text { reading }^{\mathrm{a}}\end{array}$ & $12.9(2.1)$ & $12.8(3.4)$ & $12.4(1.9)$ & $p=.883$ \\
\hline Ravens SS ${ }^{\mathrm{b}}$ & $7.5(1.3)$ & $7.6(1.1)$ & $7.1(0.6)$ & $p=.768$ \\
\hline
\end{tabular}

in Dutch, whereas other vowels are slightly inconsistent ("u," "e," and "y") or visually divergent ("i").

Speech sounds were digitally recorded (sampling rate $44.1 \mathrm{kHz}, 16$-bit quantization) from a Dutch female speaker. Recordings were band-pass filtered (180$10.000 \mathrm{~Hz}$ ), resampled at $22.05 \mathrm{kHz}$, and matched for loudness with Praat software (Boersma \& Weenink, 2002). The sounds were presented binaurally through loudspeakers at about $65 \mathrm{~dB}$ SPL. The letter was presented in white on a black background in the center of a computer screen for $500 \mathrm{msec}$, printed in lowercase font "Arial" at font size 40, approximately $1.5 \mathrm{~cm}$ high and $1 \mathrm{~cm}$ wide. The distance from the screen to the subject was kept at $70 \mathrm{~cm}$. Consequently, stimuli had a visual angle of approximately $1.2^{\circ}$ by $0.8^{\circ}$. During fixation periods, a white fixation cross was presented in the center of the screen. The visually presented letter was always an "a," irrespective of whether the standard speech sound /a/ or the deviant speech sound /o/ was presented.

\section{Design and Procedure}

In total, we conducted three different experiments, one auditory and two audiovisual experiments. In all three experiments, subjects were exposed to the speech sounds /a/ (standard, 90\%) and /o/ (deviant, 10\%). In the auditory experiment, subjects were exposed to these speech sounds while watching a silent movie (Figure 1A). In the two audiovisual experiments, subjects were exposed to the same speech sounds, while watching single letters (Figure 1B). Children were instructed not to move their eyes and sit quietly. To ensure subjects' consistent perception of the letters, in the audiovisual experiments, periodically a full color picture of a present appeared in between trials. Children were instructed to press a button when this picture was presented. The two audiovisual experiments differ only with regard to the SOA between the presentation of the letter and the speech sound. The letter appeared simultaneously $\left(\mathrm{AV}_{0}\right)$ with the speech sound or 200 msec earlier $\left(\mathrm{AV}_{200}\right)$. Each experiment consisted of four experimental blocks with 534 trials each. Trial length was always $1250 \mathrm{msec}$.

\section{Data Recording and Statistical Analysis}

EEG data were recorded in a sound-attenuating and electrically shielded room $(0.01-50 \mathrm{~Hz}$, sampling rate $250 \mathrm{~Hz}$ ) from 30 electrode positions (Extended International 10-20 system; Nuwer et al., 1998) relative to a nose reference. Eye movements and blinks were measured with bipolar VEOG/HEOG channels. All electrode impedance levels (EEG and EOG) were kept below $5 \mathrm{k} \Omega$. EEG data were epoched from -50 to $850 \mathrm{msec}$ relative to stimulus onset, baseline corrected $(50 \mathrm{msec}$ prestimulus interval), and 1-30 Hz band-pass filtered (NeuroScan 4.2). Epochs containing data exceeding a 
maximum voltage criterion of $75 \mu \mathrm{V}$ were rejected. Standards immediately following deviants were not included in the analyses. The raw EEG data were corrected for vertical eye movements (i.e., blink artifacts; (Semtlitsch, Anderer, Schuster, \& Presslich, 1986)). Subjects with over $30 \%$ rejected epochs (i.e., 60 epochs on a total of 200 per condition) were excluded from analysis. Considering the beginner readers: In the auditory experiment, the mean number of accepted epochs in the grand averages for standards and deviants were 162 (SD 14) and 161 (SD 15); in $\mathrm{AV}_{0} 172$ (SD 20) and 174 (SD 19), respectively; in $\mathrm{AV}_{200} 163$ (SD 21) and 163 (SD 17), respectively. Considering the advanced readers: in the auditory experiment, the mean number of accepted epochs in the grand averages for standards and deviants were 173 (SD 17) and 173 (SD 17); in $\mathrm{AV}_{0} 174$ (SD 19) and 177 (SD 18), respectively; in $\mathrm{AV}_{200} 178$ (SD 20) and 179 (SD 18), respectively. The resulting cleaned datasets did not show any noticeable confounds due to motion or eyemovement artifacts and, accordingly, no noticeable age group differences. Epochs were averaged separately for each condition and each participant. Difference waves are calculated by subtracting the ERPs to the standard condition from ERPs to the deviant condition.

Statistical analyses were performed on 11 electrodes covering the fronto-central (Fz, Cz, FC3, FC4), temporal (T3 and $\mathrm{T} 4)$, parietal (CP3 and $\mathrm{CP} 4)$, and occipital $(\mathrm{Oz}$, $\mathrm{O} 1$ and $\mathrm{O} 2)$ regions of the brain to investigate the auditory MMN. From the difference waveforms, we derived two dependent variables for each electrode: (I) the MMN latency measured at the maximum amplitude of the MMN in the latency range from 50 to $250 \mathrm{msec}$ poststimulus onset and (II) the MMN amplitude measured as the mean amplitude across 50 msec centered around the individual peak latency (separately for each subject, condition and electrode). In the present study, we used the mean area amplitude rather than the peak amplitude as it is considered a more reliable measure. Consequently, in the present study, the term amplitude always refers to the mean area amplitude. The analysis on 11 electrodes was followed by a detailed analysis on the fronto-central electrodes (Fz, Cz, FC3, FC4), where the MMN effect was most prominent. All reported $p$ values from the repeated measures ANOVA were Greenhouse-Geisser corrected.

\section{RESULTS}

\section{Beginner Readers}

\section{Auditory Experiment}

We first analyzed the auditory experiment to probe a typical MMN evoked by a deviant speech sound in a standard speech sound context. Figure $2 \mathrm{~A}$ shows grandaverage ERPs for standard and deviant stimuli and difference waveforms (deviant - standard stimuli) obtained in the auditory experiment as measured at the fronto- central electrode sites (Fz, Cz, FC3, FC4). The speech sound deviant elicited an MMN with average peak latency of $155 \mathrm{msec}$ (averaged over the four fronto-central electrodes, 53 msec $S D$ ) after the onset of the auditory stimulus, with a topographical distribution (Figure 2A) that is typically reported for the MMN (Picton et al., 2000; Schröger, 1998).

Amplitude properties of ERP activity in the MMN time window were first analyzed using a 2 (stimulus type; standard versus deviant) $\times 11$ (electrode sites) repeated measures ANOVA. We found a marginally significant interaction with electrode site $[F(10,120)=2.95, p=$ .056; Figure 3]. Because we expected an interaction of stimulus type with electrode, we further analyzed only the four fronto-central electrodes, where the MMN is expected to be most pronounced. The same analysis on only the four fronto-central electrodes revealed no significant interaction between stimulus type and electrode $[F(3,36)=7.58, p=.46]$, and a main effect of stimulus type for mean amplitude values in the $50-\mathrm{msec}$ window around the individual peaks $[F(1,12)=7.38$, $p=.019]$. The deviant grand-average waves were systematically more negative in comparison with standard grand-average waves (Figure 2A; dark gray rectangle). Analysis of the difference waves with a one-sample $t$ test revealed significant differences from zero at all four fronto-central electrode sites, indicating a typical MMN evoked by deviant speech sounds in beginner readers: at Fz, $t(12)=-5.66, p<.001 ;$ at $\mathrm{Cz}, t(12)=-4.91$, $p<.001 ;$ at FC3, $t(12)=-5.92, p<.001 ;$ and at FC4, $t(12)=-5.38, p<.001$.

\section{Auditory versus Audiovisual Experiments}

In all three experiments (the auditory experiment and both audiovisual experiments $\mathrm{AV}_{0}$ and $A V_{200}$ ), the deviant speech sound stimulus elicited a negativity with an average peak latency (averaged over the four fronto-central electrodes) at $165 \mathrm{msec}(57 \mathrm{msec} S D$ ) after auditory stimulus onset (Figure 2; dark gray rectangle), with a typical topographical distribution of the MMN. Average peak latencies (averaged over the four fronto-central electrodes) were $156 \mathrm{msec}(44 \mathrm{msec} S D)$ for $\mathrm{AV}_{0}$ and $181 \mathrm{msec}(68 \mathrm{msec}$ $S D)$ for $\mathrm{AV}_{200}$ after the onset of the auditory stimulus.

Amplitude and latency properties of ERP activity in the MMN time window were first analyzed using a mixed ANOVA with two within-subject factors, stimulus type (2) and electrode sites (11), and one between-group variable, experiment (3). We analyzed the responses reflecting stimulus mismatch. There was a significant interaction between stimulus type and electrode $[F(10$, $390)=3.57, p=.010]$. When the same analysis was performed on only the four fronto-central electrodes, there is no significant interaction with electrodes $[F(3$, $117)=2.65, p=.057]$. There was no significant interaction between stimulus type and experiment, indicating comparable MMN effects in each of the three 
Figure 2. Grand-average ERPs for the standard (dotted lines) and deviant stimuli (dashed lines), difference waves (solid lines) as measured at $\mathrm{Cz}$, and MMN maps for the auditory experiment (A) and the two audiovisual experiments 0 msec SOA (B) and $200 \mathrm{msec}$ SOA (C) with beginner readers.

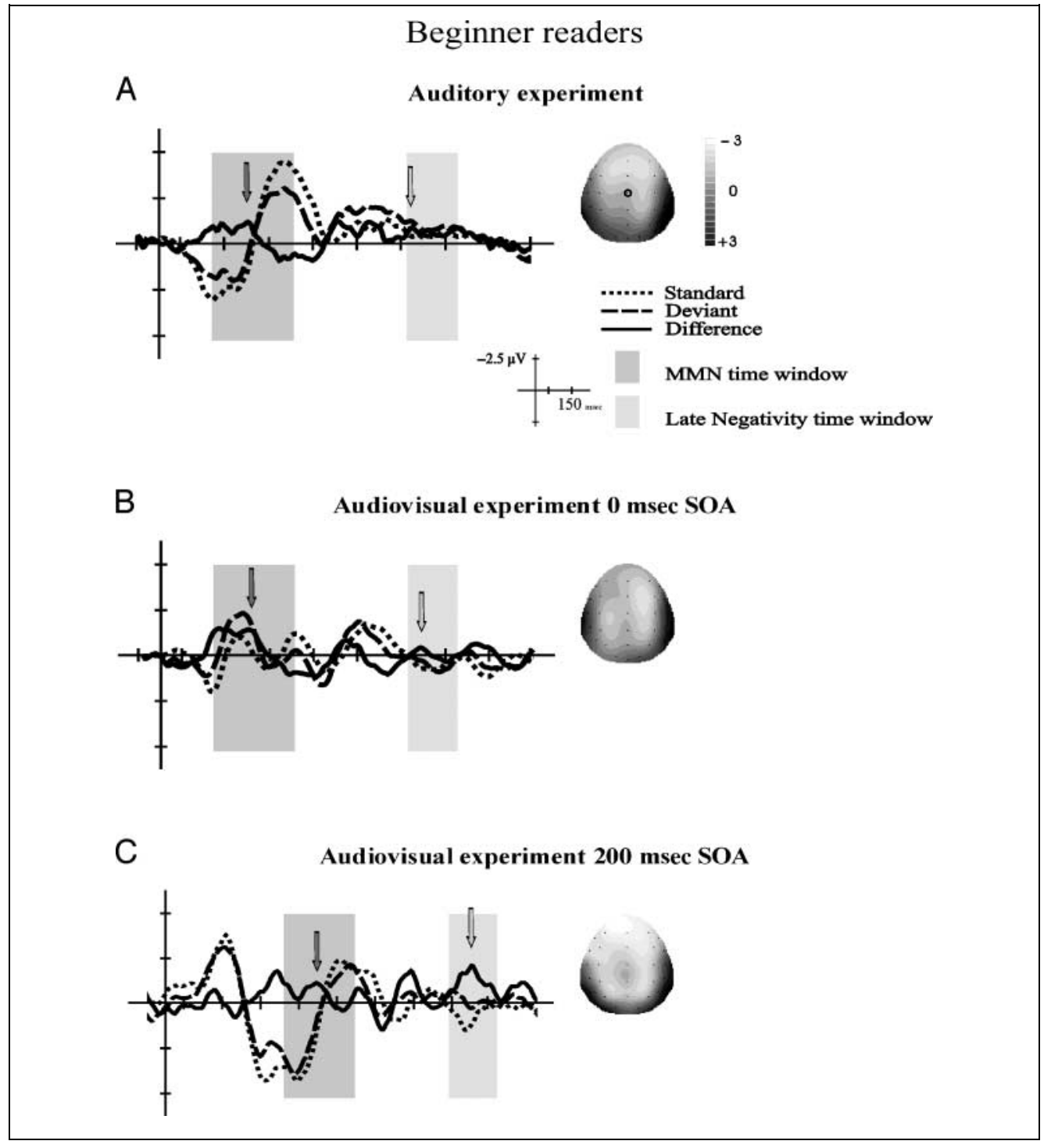

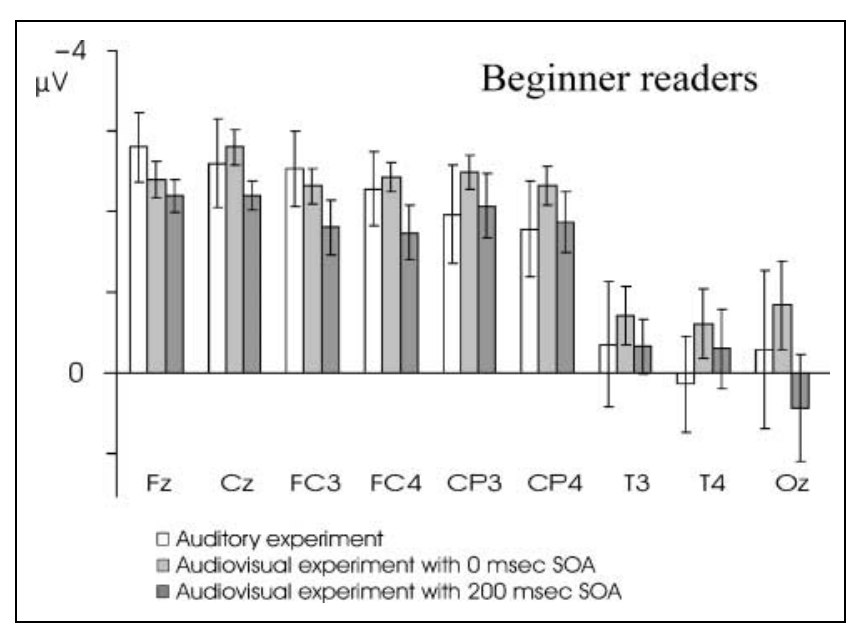

Figure 3. Mean amplitude values over $50 \mathrm{msec}$ around the individually assessed MMN peak with standard error for 9 electrodes included in the analysis of beginner readers (Fz, Cz, FC3, FC4, CP3, CP4, T3, $\mathrm{T} 4$, and $\mathrm{Oz}$ ). experiments $[F(1,39)=2.61, p=.086]$. The MMN effect was reflected by a significantly stronger negative ERP response to the deviant stimuli in comparison with the standard stimuli [main effect of stimulus type for mean amplitude, $F(1,39)=28.73, p<.001]$.

Table 2 shows the peak latency and mean area amplitude measures of the difference waves on the four fronto-central electrodes evoked by the auditory deviant in the auditory experiment and in both audiovisual experiments, $\mathrm{AV}_{0}$ and $\mathrm{AV}_{200}$. The latency values are reported with respect to the onset of the auditory stimulus. Repeated measures ANOVA on the latency of the MMN over the experiments did not show a significant effect on latency $(F<1)$. Repeated measures ANOVA on amplitude of the difference waves of the fronto-central electrodes revealed no significant effect of experiment $[F(2,39)=1.32, p=.279$; Figure 3$]$, indicating no differences in the MMN as evoked in the auditory experiment versus the audiovisual experiments. The difference 
Table 2. Peak Latency and Mean Area Amplitude Measures on the Four Fronto-central Electrodes with Standard Errors of the Mean of Beginner Readers for the Three Experiments

\begin{tabular}{llcc}
\hline $\begin{array}{l}\text { Difference } \\
\text { Waves }\end{array}$ & Auditory & Audiovisual & Audiovisual \\
\hline
\end{tabular}

Peak Latency \pm SE (msec)

$\begin{array}{llll}\text { Fz } & 164 \pm 15.3 & 152 \pm 9.1 & 186 \pm 21.1 \\ \text { Cz } & 152 \pm 14.9 & 157 \pm 12.3 & 180 \pm 20.9 \\ \text { FC3 } & 154 \pm 15.6 & 158 \pm 12.8 & 180 \pm 17.6 \\ \text { FC4 } & 152 \pm 15.1 & 159 \pm 13.3 & 179 \pm 18.0\end{array}$

Mean Area $\pm S E(\mu \mathrm{V})$

\begin{tabular}{lllr} 
Fz & $-2.8 \pm 0.5$ & $-2.4 \pm 0.3$ & $-2.2 \pm 0.2$ \\
$\mathrm{Cz}$ & $-2.6 \pm 0.4$ & $-2.8 \pm 0.2$ & $-2.2 \pm 0.2$ \\
$\mathrm{FC} 3$ & $-2.6 \pm 0.4$ & $-2.3 \pm 0.2$ & $-1.7 \pm 0.3$ \\
$\mathrm{FC} 4$ & $-2.4 \pm 0.5$ & $-2.5 \pm 0.2$ & $-1.8 \pm 0.3$ \\
\hline
\end{tabular}

waves revealed, however, an interesting difference between the three experiments at a negativity around $650 \mathrm{msec}$ after auditory stimulus onset (Figure 2; light gray rectangle). The analysis of this negativity, referred to as the late negativity, is presented below.

\section{Advanced Readers \\ Auditory Experiment}

We analyzed the auditory experiment to probe a typical MMN in advanced readers and compared these results with the MMN evoked by beginner readers. Figure $4 \mathrm{~A}$ shows the grand-average ERPs and difference waveforms (deviant - standard stimuli) for the speech sound deviant in the auditory experiment. The speech sound deviant elicited an MMN with average peak latency of $152 \mathrm{msec}$ (averaged over the four fronto-central electrodes, $45 \mathrm{msec} S D$ ) after the onset of the auditory stimulus, with a topographical distribution (Figure 4A) typical for the MMN (Picton et al., 2000; Schröger, 1998).
Figure 4. Grand-average ERPs for the standard (dotted lines) and deviant stimuli (dashed lines), difference waves (solid lines) as measured at $\mathrm{Cz}$, and MMN maps for the auditory experiment (A) and the two audiovisual experiments 0 msec SOA

(B) and $200 \mathrm{msec} \mathrm{SOA}$

(C) with advanced readers.

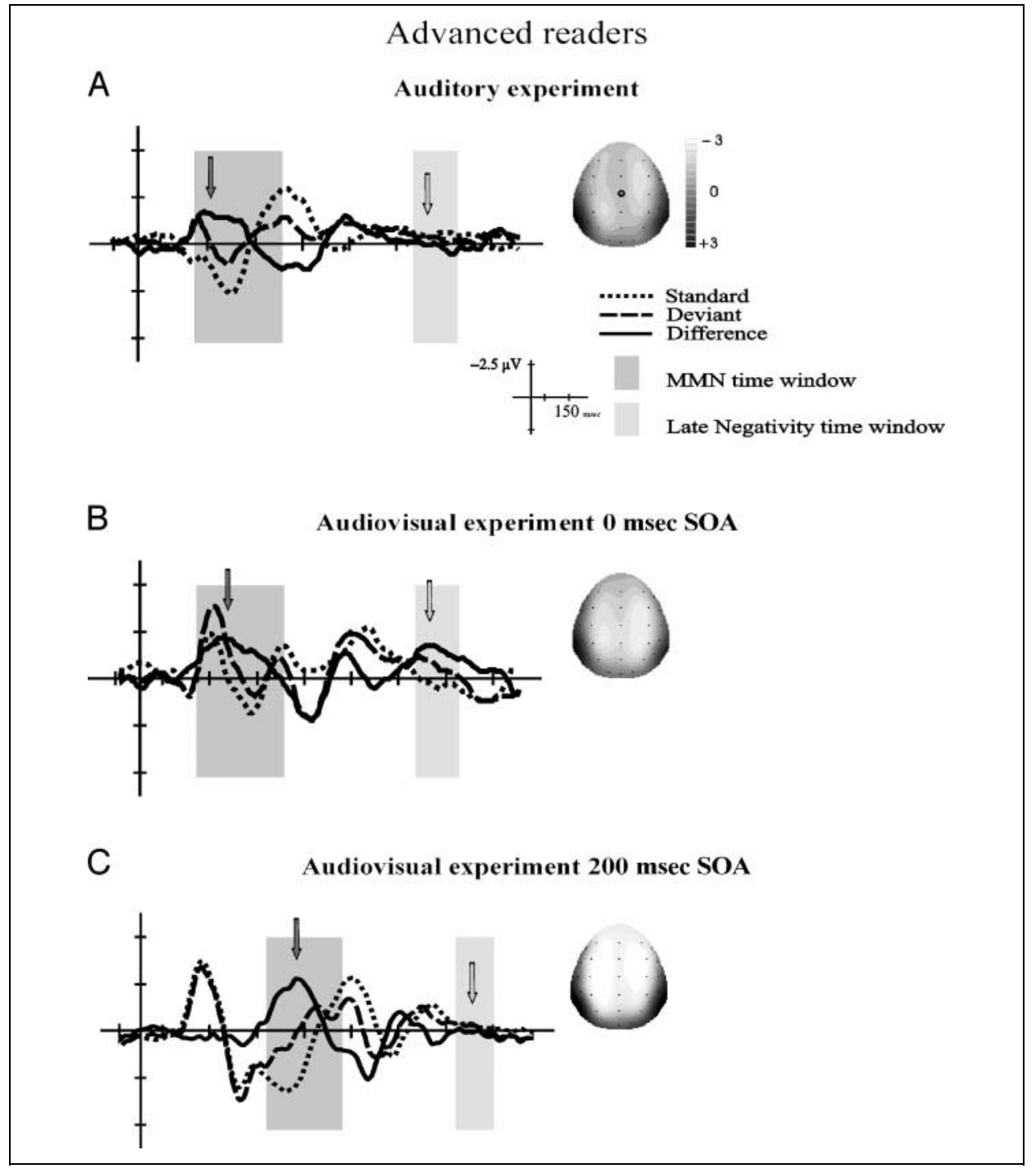


Amplitude properties of brain waves in the MMN time window were first analyzed using a 2 (stimulus type; standard vs. deviant) $\times 11$ (electrode sites) repeated measures ANOVA. We found a significant interaction with electrode site $[F(10,110)=10.74, p=.001$; Figure 5]. When we analyzed only the four fronto-central electrodes, there was no longer a significant interaction between stimulus type and electrode $[F(3,33)=2.41, p=$ .098]. We found a main effect of stimulus type for mean amplitude values in the 50 -msec window around the individual peaks $[F(1,11)=26.65, p<.001]$. The deviant grand-average waves were systematically more negative in comparison with standard grand-average waves (Figure 4; dark gray rectangle). Analysis of the difference waves with a one-sample $t$ test revealed significant differences from zero in all four fronto-central electrodes, indicating a typical MMN evoked by deviant speech sounds in advanced readers: at $\mathrm{Fz}, t(11)=-5.84, p<.001$; at $\mathrm{Cz}, t(11)=-6.34, p<.001$; at FC3, $t(11)=-3.51, p=$ $.005 ;$ and at FC4, $t(11)=-6.04, p<.001$.

\section{Auditory versus Audiovisual Experiments}

In all three experiments (the auditory experiment and both audiovisual experiments, $A_{0}$ and $A V_{200}$ ), the deviant speech sound stimulus elicited a negativity with an average peak latency (averaged over the four frontocentral electrodes) at $166 \mathrm{msec}(41 \mathrm{msec} S D)$ after auditory stimulus onset (Figure 4; dark gray rectangle), with a typical topographical distribution of the MMN. Average peak latencies (averaged over the four frontocentral electrodes) were $181 \mathrm{msec}(42 \mathrm{msec} S D)$ for $\mathrm{AV}_{0}$ and 163 msec (33 msec SD) for $\mathrm{AV}_{200}$ after the onset of the auditory stimulus. We first analyzed the responses reflecting stimulus mismatch with a repeated measures ANOVA with stimulus type (2) and electrode (11) as

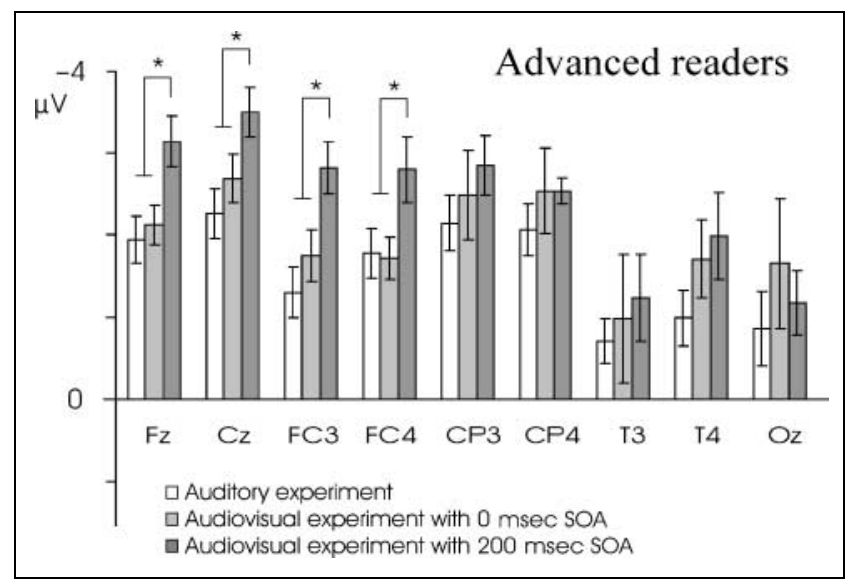

Figure 5. Mean amplitude values over $50 \mathrm{msec}$ around the individually assessed MMN peak with standard error for 9 electrodes included in the analysis with advanced readers (Fz, Cz, FC3, FC4, CP3, CP4, T3, $\mathrm{T} 4$, and $\mathrm{Oz}$ ). Significant differences $(p<.05)$ in mean amplitude measures are indicated per electrode by an asterisk.
Table 3. Peak Latency and Mean Area Amplitude Measures on the Four Fronto-central Electrodes with Standard Errors of the Mean of Advanced Readers for the Three Experiments

\begin{tabular}{lccc}
\hline Difference & Audiovisual & Audiovisual \\
Waves & Auditory & O msec SOA & 200 msec SOA \\
\hline
\end{tabular}

Peak Latency $\pm S E$ (msec)

$\begin{array}{llll}\text { Fz } & 136 \pm 14.4 & 178 \pm 13.3 & 166 \pm 11.1 \\ \text { Cz } & 146 \pm 14.1 & 172 \pm 12.9 & 163 \pm 9.5 \\ \text { FC3 } & 148 \pm 15.6 & 189 \pm 12.5 & 161 \pm 10.9 \\ \text { FC4 } & 151 \pm 13.0 & 184 \pm 13.9 & 162 \pm 11.9\end{array}$

Mean Area $\pm S E(\mu V)$

\begin{tabular}{llll} 
Fz & $-2.2 \pm 0.4$ & $-2.3 \pm 0.3$ & $-3.1 \pm 0.2$ \\
Cz & $-2.6 \pm 0.4$ & $-2.8 \pm 0.3$ & $-3.5 \pm 0.3$ \\
FC3 & $-1.4 \pm 0.3$ & $-1.8 \pm 0.3$ & $-2.8 \pm 0.3$ \\
FC4 & $-2.0 \pm 0.4$ & $-1.9 \pm 0.3$ & $-2.8 \pm 0.4$ \\
\hline
\end{tabular}

within-subject factors and experiment (3) as a betweensubject factor. There was a significant interaction between stimulus type and electrode $[F(10,340)=15.95$, $p<.001$; Figure 5]. The same analysis on only the four fronto-central electrodes revealed no significant interaction with electrodes $[F(3,102)=1.35, p=.27]$. More importantly, there was a significant interaction between stimulus type and experiment $[F(2,34)=5.30, p=.010]$, indicating a different MMN over the three experiments. Despite this interaction, the ERP response to the deviant stimuli was consistently more negative in comparison to the standard stimuli in all three experiments [main effect of stimulus type for mean amplitude $F(1,34)=108.62$, $p<.001]$.

Table 3 shows the peak latency and mean area amplitude measures of the difference waves for the four fronto-central electrodes evoked by the auditory deviant in the auditory experiment and in both audiovisual experiments. The latency values are reported with respect to the onset of the auditory stimulus. Repeated measures ANOVA on the latency of the MMN over the experiments did not show a significant effect of latency $[F(2,34)=1.51, p=.235]$. Repeated measures ANOVA on the mean of the four difference waves of the frontocentral electrodes revealed a marginally significant effect of experiment $[F(2,32)=3.24, p=.052]$. Because we had a priori expectations about the direction of the differences between the experiments (enhancement of the MMN to the deviant speech sound when presented in the context of a letter in comparison with presentation in isolation), we calculated contrasts of the mean values of the MMN to analyze these differences in detail. In contrast with our expectations, planned contrasts revealed that the context of letters in $\mathrm{AV}_{0}$ did not significantly increase the amplitude of the MMN to the 
auditory deviant in comparison with no letter context $[t(31)=1.046, p=.324]$. In $\mathrm{AV}_{200}$, however, the amplitude of the MMN to the auditory deviant significantly increased in comparison with the MMN amplitude in the auditory experiment $[t(31)=2.351, p=.025$; Figure $6 \mathrm{~B}$, left set of bar graphs]. Contrasting the MMN amplitude in $\mathrm{AV}_{0}$ with the $M M N$ in $\mathrm{AV}_{200}$ revealed a marginally significant difference $[t(31)=2.005, p=.053$; Figure $6 \mathrm{~B}$, left set of bar graphs], indicating an effect of SOA in the advanced readers. This effect of SOA is, however, reversed if compared with the SOA effect in the experienced adult readers (Figure 6; dark gray rectangle) (Froyen et al., 2008). The difference waves also revealed an interesting difference between the three experiments at a negativity around $650 \mathrm{msec}$ after auditory stimulus onset (Figure 4; light gray rectangle). The analysis of this negativity observed in beginner and advanced readers is presented below.

\section{Stable Auditory MMN Early in Development}

To ascertain that both beginner and advanced readers elicited a comparable MMN in the auditory experiment, we performed a one-way ANOVA comparing the difference waves of the beginner readers with the difference waves of the advanced readers. This analysis revealed no significant differences considering mean or latency area value of the MMN $[F(2,24)=1.49, p=.246$ and $F<$ 1 , respectively]. We also performed a one-way ANOVA comparing the difference waves of the beginner readers and the advanced readers with the difference waves of the experienced adult readers from our earlier study (Froyen et al., 2008). This analysis revealed no significant differences for the mean or latency values of the MMN (Figure 6; dark gray rectangle), $F<1$ and $F<1$, respectively, indicating a stable auditory MMN resembling the adult MMN already early in development.

\section{Late Negativity}

The difference waves revealed another interesting difference between the three experiments around $650 \mathrm{msec}$ after auditory stimulus onset in both the beginner and advanced readers (Figure 6; light gray rectangle). We therefore tested this negativity statistically within each age group with a repeated measures ANOVA, with four fronto-central electrodes (Fz, Cz, FC3, and FC4) as a within-subject factor and experiment as a betweensubject factor. The dependent variable was the mean of $50 \mathrm{msec}$ around the peak values between 600 and $700 \mathrm{msec}$ after auditory stimulus onset, established per subject for each electrode in each experiment.

In the beginner readers, there was a marginally significant main effect of experiment $[F(2,39)=3.235$,
Figure 6. Difference waves on the fronto-central electrode $\mathrm{Cz}$ as measured in the auditory and the audiovisual experiments for beginner, advanced (this study), and experienced adult readers (Froyen et al., 2008) with the different time windows of the MMN, the late mismatch negativity (IMMN), and the late negativity indicated in rectangles (1). Mean amplitude values with standard error for the MMN (left) and the late negativity (right) averaged over the four fronto-central electrodes $\mathrm{Fz}, \mathrm{Cz}, \mathrm{FC} 3$, and FC4 for beginner, advanced (this study), and experienced adult readers (Froyen et al., 2008) (2). Significant differences $(p<.05)$ are indicated with an asterisk.

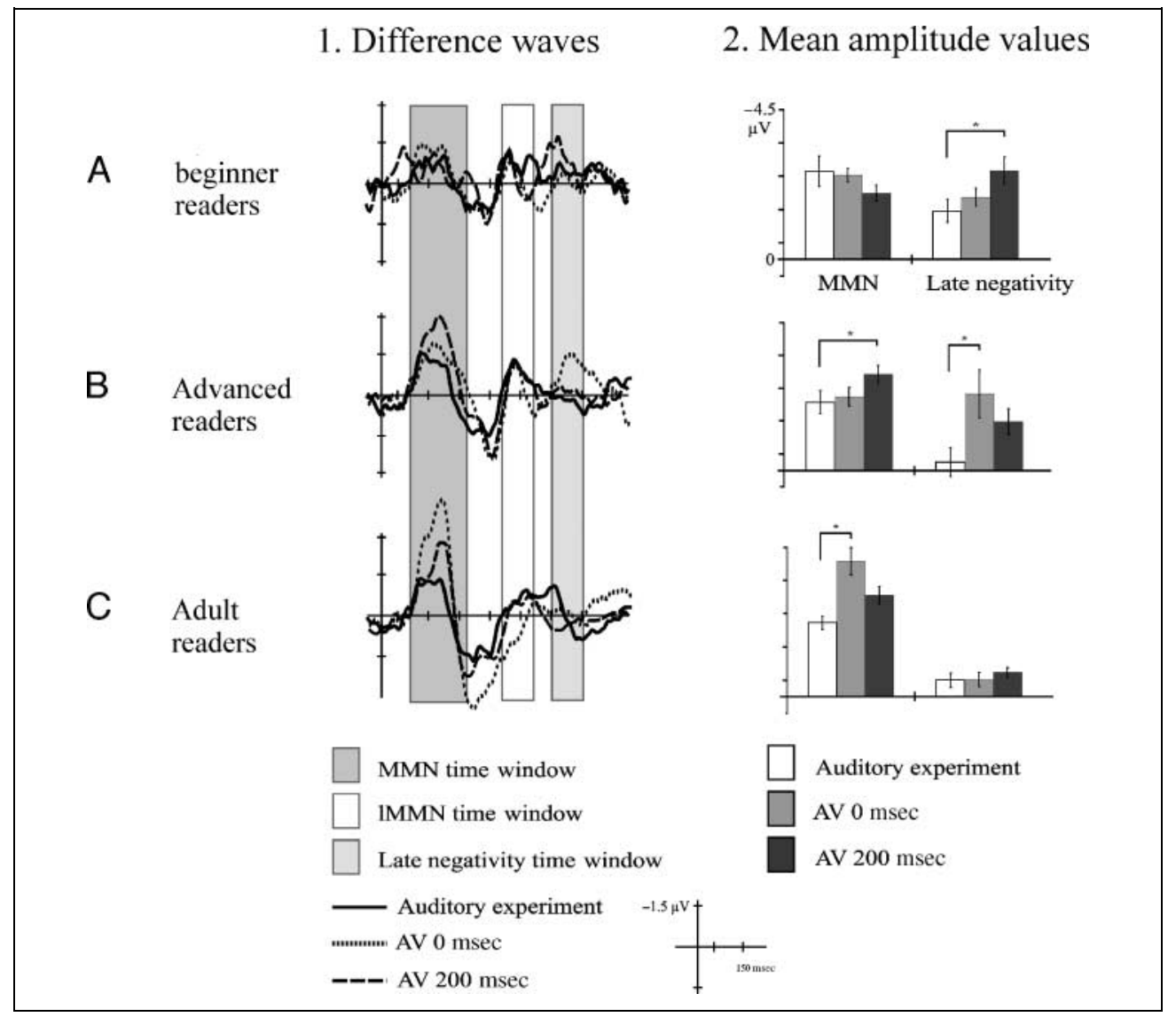


$p=.050]$. Post hoc $t$ tests (Tukey corrected) revealed a significant difference between the auditory and the audiovisual experiment $\mathrm{AV}_{200}[t(39)=1.215, p=.045]$, but no significant differences between the auditory and audiovisual experiment $\mathrm{AV}_{0}[t(39)=0.4083, p=.693]$, or between both audiovisual experiments $\mathrm{AV}_{0}$ and $\mathrm{AV}_{200}$ $[t(39)=0.8069, p=.226]$. Apparently, at $650 \mathrm{msec}$ after speech sound onset, there is an influence of letter context on speech sound processing in beginner readers, but only when the letter is presented 200 msec before the speech sound. In the advanced readers, we also found a main effect of experiment $[F(2,31)=$ $3.562, p=.038$ ]. Post hoc $t$ tests (Tukey corrected) revealed a significant difference between the auditory experiment and the audiovisual experiment $\mathrm{AV}_{0}[t(31)=$ $2.074, p=.031]$, and no differences between the auditory experiment and $\mathrm{AV}_{200}[t(31)=1.361, p=.188]$, or between $\mathrm{AV}_{0}$ and $\mathrm{AV}_{200}[t(31)=0.7131, p=.632]$. Advanced readers show an influence of letter context on speech sound processing around $650 \mathrm{msec}$ after auditory speech sound onset, but unlike beginner readers, only when the letter is presented simultaneously with the speech sound.

The negativity described here probably does not reflect the late mismatch negativity or IMMN as described in earlier studies (Cheour, Korpilahti, Martynova, \& Lang, 2001; Korpilahti, Krause, Holopainen, \& Lang, 2001). The IMMN is also revealed in the present data between 450 and 500 msec after auditory stimulus onset (Figure 6; white rectangle), a typically reported latency (Cheour et al., 2001; Korpilahti et al., 2001). We tested the IMMN statistically within each age group with a repeated measures ANOVA, with four fronto-central electrodes (Fz, Cz, FC3, and FC4) as a within-subject factor and experiment as a between-subject factor. The dependent variable was the mean of $50 \mathrm{msec}$ around the peak values between 400 and $500 \mathrm{msec}$ after auditory stimulus onset, established per subject for each electrode in each experiment. Neither the beginner readers nor the advanced readers revealed an effect of experiment in this time window $[F(2,39)=1.211, p=.309$ and $F<0.1$, respectively].

\section{DISCUSSION}

An MMN paradigm was used to study the development of letter-speech sound integration. The influence of letters on speech sound processing was investigated in beginner and advanced readers. In order to investigate the temporal window for letter-speech sound processing during development, we manipulated SOA. The letter was presented either simultaneously with the speech sound or 200 msec before the speech sound. The data revealed unexpected results at an MMN latency around $150 \mathrm{msec}$ and at a later latency around 650 msec.
In order to assure a standard MMN in all age groups, we compared the MMN evoked to speech sounds in the auditory experiment with beginner, advanced, and also experienced adult readers (Froyen et al., 2008). All groups elicited a typical MMN in terms of amplitude, latency, and topographical distribution (Picton et al., 2000; Schröger, 1998). Moreover, no differences were found in amplitude, latency, or topographical distribution between the groups, which confirmed the suggestion of a stable MMN resembling the adult MMN being already present early in development (Csépe, 2003).

Next, the influence of letters on speech sound processing was investigated in beginner readers. Comparing the MMN in the auditory experiment with the MMN in the audiovisual experiments revealed no differences in amplitude, latency, or topographical distribution. This indicates that after approximately one year of reading instruction letters do not influence early speech sound processing, and thus, there is no indication of any form of automation of letter-speech sound processing. This does not seem to be consistent with the current educational Dutch standards requiring full mastery of letterspeech sound associations within one year of reading instruction (Wentink \& Verhoeven, 2003). These results, therefore, reveal that fully developed letter-speech sound processing requires more than just accurate association. Consistent with the reaction time data reported in Blomert and Vaessen (in press), these results point to an extended period of development which continues after the first year of reading instruction.

In advanced readers, comparison of the MMN in the auditory experiment with the MMN in the audiovisual experiments revealed a cross-modal enhancement of the MMN amplitude, but only when letters were presented 200 msec earlier in comparison with the speech sounds $\left(\mathrm{AV}_{200}\right)$. Because the $\mathrm{MMN}$ is an early and automatically evoked ERP component, we suggest that early speech sound processing in advanced readers is automatically influenced by the presentation of a letter. However, advanced readers exhibited no differences in MMN, and thus, no sign of integration when the letter was presented simultaneously with the speech sound $\left(\mathrm{AV}_{0}\right)$. This contrasts sharply with the results from experienced adult readers only showing automatic integration if letters and speech sounds were presented simultaneously, and not if presented at 100 or $200 \mathrm{msec}$ SOA (Froyen et al., 2008). Advanced readers show an influence of letters on the processing of speech sounds, but in a different temporal window for integration than experienced adult readers, indicating that even after 4 years of reading instruction letter-speech sound processing continues to develop.

Although the auditory experiment differs in visual aspects from the audiovisual experiments, it is unlikely that these differences are responsible for the present results. The MMN is known to be a very basic auditory deviance detection mechanism of the brain (Schröger, 
1998). The similarity in morphology, latency, and topographical distribution of the MMNs in the auditory and audiovisual experiments in both age groups suggests a similar underlying neural mechanism. Moreover, the difference in amplitude, as the measure of interest, seems not explainable by the differences in visual aspects between the auditory and the audiovisual experiment. Considering the advanced readers: The MMN evoked in $\mathrm{AV}_{0}$ did not differ in any way, with the MMN evoked in the auditory experiment, despite differences in visual aspects between the two experiments. Furthermore, the $\mathrm{MMN}$ amplitude in $\mathrm{AV}_{200}$ was significantly higher in comparison with the $\mathrm{MMN}$ amplitude in $\mathrm{AV}_{0}$. Visual aspects could not have affected this difference in MMN amplitude because visual aspects were identical in both audiovisual experiments.

Interestingly, we also observed a noticeable pattern of amplitude enhancement of the difference waves at $650 \mathrm{msec}$ after speech sound onset (Figure 6). As described in the Results, we distinguish the negativity observed at $650 \mathrm{msec}$ from the late mismatch negativity or IMMN described in earlier studies (Cheour et al., 2001; Korpilahti et al., 2001). The IMMN is evoked between 400 and 450 msec after auditory stimulus onset, which is earlier in comparison with the negativity considered here. Because the exact nature of the negativity observed at $650 \mathrm{msec}$ is as yet unclear, we will refer to it as "late negativity." In combination with the results from the MMN, the pattern of the late negativity amplitudes in beginner and advanced readers revealed a complex but systematic development of letter-speech sound processing. The beginner readers exhibited an enhancement of the late negativity amplitude in $\mathrm{AV}_{200}$ in comparison with the amplitude of the late negativity in the auditory experiment (Figure 6A; light gray rectangle). Remarkably, the observed trend of late negativity amplitudes in the beginner readers resembles the pattern of MMN amplitudes in the advanced readers: enhancement of the $\mathrm{MMN}$ amplitude in $\mathrm{AV}_{200}$ in comparison with the MMN amplitude in the auditory (Figure 6B; dark gray rectangle). Thus, while for beginner readers there is no indication of an influence of the letter "early" during speech sound processing, beginner readers do reveal an influence of the letter "later" during speech sound processing, at $\mathrm{SOA}_{200}$. In the advanced readers, enhancement of the late negativity amplitude was revealed in the audiovisual experiment $\mathrm{AV}_{0}$ in comparison with the late negativity amplitude in the auditory experiment (Figure 6B; light gray rectangle). The observed pattern of late negativity amplitudes in the advanced readers resembles the pattern of MMN amplitudes in the experienced adult readers remarkably well (Froyen et al., 2008), with an enhancement of the MMN amplitude in $\mathrm{AV}_{0}$ in comparison with the MMN amplitude in the auditory experiment (Figure 6C; dark gray rectangle). The observed pattern of late negativity amplitudes indicates "adult-like" letter-speech sound processing in advanced readers, however, at a later latency; $650 \mathrm{msec}$ instead of $150 \mathrm{msec}$ after speech sound onset.

Considering the changes in MMN and in late negativity amplitudes, there seems to be a double shift in timing properties during the development of letter-speech sound processing, both in the latency at which letterspeech sound processing occurs and in the temporal window of integration (i.e., SOA). Data from our previous study reveal early and automatic integration in the experienced adult readers only if letters and speech sounds were presented simultaneously (SOA of $0 \mathrm{msec}$ ) (Figure 6C) (Froyen et al., 2008). In contrast, the beginner readers show no sign of integration but only a late influence of letters on speech sound processing; around $650 \mathrm{msec}$ after presentation of the speech sounds, and only at an SOA of $200 \mathrm{msec}$ between the presentation of letters and speech sounds (Figure 6A). The advanced readers show early and automatic integration around $150 \mathrm{msec}$, however, only at an SOA of $200 \mathrm{msec}$ (Figure 6B), which is still at a different temporal window for integration in comparison with the experienced adult readers. Advanced readers showed a more "adult-like" temporal window for integration, that is, integration at $0 \mathrm{msec}$ SOA and not at $200 \mathrm{msec}$ SOA, but only $650 \mathrm{msec}$ after auditory stimulus onset (Figure 6B). This double shift in timing properties may be interpreted as a neural fine-tuning of letter-speech sound processing extending far beyond the early school years, most likely caused by continued brain maturation interacting with increasing reading experience. Continuing pruning and myelination in the temporal lobes, containing speech-related areas, indicates brain maturation beyond adolescence (Casey, Tottenham, Liston, \& Durston, 2005; Sowel et al., 2003). At the same time, the brain is subject to rapidly increasing reading experience from the first school year on.

The shift in SOA from 200 to 0 msec indicates a shift of the temporal window of letter-speech sound integration over development. This is consistent with the observation of changing temporal windows for processing audiovisual stimuli from childhood to adulthood (Laasonen et al., 2000, 2002).

The shift in latency at which letter-speech sound processing occurs, namely, from $650 \mathrm{msec}$ after speech sound onset in beginner and advanced readers to 150 msec after speech sound onset in advanced and experienced adult readers (Froyen et al., 2008), does not seem to be an effect of straightforward brain maturation. It is generally assumed that ERP response latencies decrease with increasing age (Bonte et al., 2007; Brem et al., 2006; Maurer et al., 2003; Shafer et al., 2000). Brem et al. (2006) relate decreasing latencies to increases in processing speed as a consequence of general brain maturation. However, the above-mentioned ERP studies always report a decrease in latency within one and the same ERP component, respectively the MMN 
(Bonte et al., 2007; Maurer et al., 2003; Shafer et al., 2000) or the N1 (Brem et al., 2006). In contrast, the present study shows no differences in the latency of the MMN, neither between younger and older children nor between children and adults. The time shift does not refer to a different latency of the same process at a different age, but probably reflects a shift between different mechanisms responsible for letter-speech sound processing in beginner, advanced, and adult readers. Additionally, letter-speech sound processing in beginner readers, as reflected in the late negativity, occurs no less than 500 msec later in comparison with fully developed letter-speech sound processing. The observed latency shift is much larger than reported in any of the above mentioned ERP studies, and thus, is unlikely to be caused by the continued decrease in processing time of the maturing brain alone. We therefore suggest that rapidly increasing experience with reading during the first years at school may affect, besides processing speed, also the nature of letter-speech sound processing. Whereas beginner readers may merely associate letters to speech sounds, increasing experience with reading may lead to automatic letter-speech sound integration. Once letter-speech sound integration is established, letter-speech sound processing by mere association becomes redundant, as reflected in a total disappearance of the late negativity effect in experienced adult readers (Froyen et al., 2008). The fact that the late negativity pattern of beginner readers (Figure 6A) resembles the early pattern in advanced readers (Figure $6 \mathrm{~B}$ ) and the late negativity pattern in advanced readers (Figure 6B) resembles the early pattern in adults (Figure 6C) underpins our suggestion. The advanced readers seem to be able to use both mechanisms depending on SOA; integration seems possible at $200 \mathrm{msec}$ SOA (early pattern), but the simultaneous presentation of letters and speech sounds (effective for adults) still seems too far fetched at this age and level of reading expertise and invokes the late association processes (late pattern), also observable in the beginner readers.

This double shift in timing properties of letter-speech sound processing during development may provide an explanation for the seemingly inconsistent results from behavioral studies. Although accurate letter-speech sound associations are established within one year of reading instruction in Dutch (Blomert \& Vaessen, in press; Wentink \& Verhoeven, 2003), reaction time data suggest protracted development beyond the early school years (Blomert \& Vaessen, in press). The present results show that the processes associating letters with speech sounds occur late in time, that is, not earlier than $650 \mathrm{msec}$ after auditory stimulus onset. In contrast, adult readers recruit only very early processes within 200 msec after stimulus onset. These findings are consistent with longer reaction times, but at the same time, do not contradict maximal accuracy already after one year of reading instruction. In sum, accuracy alone does not appear to be a sensitive indicator for letter-speech sound integration. The present brain findings are more consistent with the reaction time results, both strongly indicating protracted development of letter-speech sound associations far beyond early school year.

In our previous fMRI studies investigating letterspeech sound processing (Van Atteveldt et al., 2004, 2007), we have used many different single letters and speech sounds (vowels: a, o, i, e, u, y, and consonants: $\mathrm{d}, \mathrm{g}, \mathrm{h}, \mathrm{k}, \mathrm{l}, \mathrm{n}, \mathrm{p}, \mathrm{r}, \mathrm{s}, \mathrm{t}, \mathrm{z})$. We have always checked the results for the different stimuli separately and our consistent observation was that all single letters/speech sounds evoked the same activation patterns and integration effects. Therefore, we believe our present selection of "a" and " $\mathrm{O}$ " is reliably representative and, consequently, generalizable to other letter-speech sound pairs.

In conclusion, despite proper knowledge of the associations between letters and their corresponding speech sounds, beginner readers have not developed early and automated integration yet. Advanced readers exhibited early and automatic integration of letters and speech sounds, however, still at a different temporal window of integration than adults. A more "adult-like" pattern is only observed hundreds of milliseconds later, indicating that even after 4 years of reading instruction, letterspeech sound integration still continues to develop. The differences in temporal windows of integration and the shifts in latency of letter-speech sound processing probably reflect a double shift in timing properties during the development of letter-speech sound processing. Continued brain maturation and reading experience most likely contribute interactively to a neural fine-tuning of letter-speech sound processing during the development toward early and automatic letterspeech sound integration.

\section{Acknowledgments}

This work was supported by grant 608/022/2005 of the Dutch Board of Health Care Insurance (College voor Zorgverzekeringen) awarded to L. B. We thank three anonymous reviewers for their constructive remarks that helped us to improve the article and Martin Frost for final editing. We thank Hanne Poelmans for assistance in data acquisition. Special thanks goes to the participating children and the schools "Aloysius" and "De Perroen" from Maastricht for their cooperation.

Reprint requests should be sent to Dries J. W. Froyen, Department of Cognitive Neuroscience, Faculty of Psychology, University of Maastricht, or via e-mail: d.froyen@psychology. unimaas.nl.

\section{REFERENCES}

Blomert, L., \& Vaessen, A. (in press). Dyslexie Differentiaal Diagnose; Cognitief onderzoek van lezen en spellen [Dyslexia differential diagnosis; cognitive investigation of reading and spelling]. Amsterdam: Boom B.V. Publishers. 
Boersma, P., \& Weenink, D. (2002). Praat 4.0: A system for doing phonetics with the computer. Amsterdam: Universiteit van Amsterdam.

Bonte, M., Poelmans, H., \& Blomert, L. (2007). Deviant neurophysiological responses to phonological regularities in speech in dyslexic children. Neuropsychologia, 45, 1427-1437.

Brem, S., Bucher, K., Halder, P., Summers, P., Dietrich, T., Martin, E., et al. (2006). Evidence for developmental changes in the visual word processing network beyond adolescence. Neuroimage, 29, 822-837.

Brus, B. T., \& Voeten, M. J. M. (1973). Een-minuuttest, vorm $A$ en $B$. Nijmegen: Berkhout.

Calvert, G. A., Brammer, M. J., \& Iversen, S. D. (1998). Crossmodal identification. Trends in Cognitive Sciences, 2, 247-253

Casey, B. J., Tottenham, N., Liston, C., \& Durston, S. (2005). Imaging the developing brain: What have we learned about cognitive development? Trends in Cognitive Sciences, 9, 104-110.

Cheour, M., Korpilahti, P., Martynova, O., \& Lang, A. H. (2001). Mismatch negativity and late discriminative negativity in investigating speech perception and learning in children and infants. Audiology and Neuro-otology, 6, 2-11.

Csépe, V. (2003). Dyslexia: Different brain, different behavior. New York: Kluwer Academic/Plenum Publishers.

Dijkstra, T., Schreuder, R., \& Frauenfelder, U. H. (1989). Grapheme context effects on phonemic processing. Language and Speech, 32, 89-108.

Ehri, L. C. (2005). Development of sight word reading: Phases and findings. In M. J. Snowling \& C. Hulme (Eds.), The science of reading: A handbook (pp. 135-154). Oxford: Blackwell Publishing.

Fox, E. (1994). Grapheme-phoneme correspondence in dyslexic and matched control readers. British Journal of Psychology, 85, 41-53.

Frith, U. (1985). Beneath the surface of developmental dyslexia. In K. E. Patterson, J. C. Marshall, \& M. Coltheart (Eds.), Surface dyslexia. London: Routledge \& Kegan-Paul.

Froyen, D., Van Atteveldt, N., Bonte, M., \& Blomert, L. (2008). Cross-modal enhancement of the MMN to speech sounds indicates early and automatic integration of letters and speech sounds. Neuroscience Letters, 430, 23-28.

Hardy, M. H., Smythe, P. C., Stennet, R. G., \& Wilson, H. R. (1972). Developmental patterns in elemental reading skills: Phoneme-grapheme and grapheme-phoneme correspondences. Journal of Educational Psychology, 63, 433-436.

Herdman, A. T., Fujioka, T., Chau, W., Ross, B., Pantev, C., \& Picton, T. W. (2006). Cortical oscillations related to processing congruent and incongruent graphemephoneme pairs. Neuroscience Letters, 399, 61-66.

Kasai, K., Nakagome, K., Iwanami, A., Fukuda, M., Itoh, K., Koshida, I., et al. (2002). No effect of gender on tonal and phonetic mismatch negativity in normal adults assessed by a high resolution EEG-recording. Cognitive Brain Research, 13, 305-312.

Korpilahti, P., Krause, C. M., Holopainen, I., \& Lang, A. H. (2001). Early and late mismatch negativity elicited by words and speech-like stimuli in children. Brain and Language, 76, 332-339.

Laasonen, M., Service, E., \& Virsu, V. (2002). Crossmodal temporal order and processing acuity in developmentally dyslexic young adults. Brain and Language, 80, 340-354.

Laasonen, M., Tomma-Halme, J., Lahti-Nuuttila, P., Service, E., \& Virsu, V. (2000). Rate of information segregation in developmentally dyslexic children. Brain and Language, 75, 66-81.

Maurer, U., Bucher, K., Brem, S., \& Brandeis, D. (2003). Development of the automatic mismatch response: From frontal positivity in kindergarten children to the mismatch negativity. Clinical Neurophysiology, 114 , 808-817.

Mitterer, H., \& Blomert, L. (2003). Coping with phonological assimilation in speech perception: Evidence for early compensation. Perception \& Psychophysics, 65, 956-969.

Näätänen, R. (2000). Mismatch negativity (MMN): Perspectives for application. International Journal of Psychophysiology, 37, 3-10.

Näätänen, R. (2001). The perception of speech sounds by the human brain as reflected by the mismatch negativity (MMN) and its magnetic equivalent (MMNm). Psychophysiology, 38, 1-21.

Näätänen, R., Paavilainen, P., Tiitinen, H., Jiang, D., \& Alho, K. (1993). Attention and mismatch negativity. Psychophysiology, 30, 436-350.

Nuwer, M., Comi, G., Emerson, R., Fuglsang-Frederiksen, A., Guérit, J., Hinrichs, H., et al. (1998). IFCN standards for digital recording of clinical EEG. Electroencephalography and Clinical Neurophysiology, 106, 259-261.

Picton, T. W., Alain, C., Otten, L., Ritter, W., \& Achim, A. (2000). Mismatch negativity: Different water in the same river. Audiology \& Neuro-otology, 5, 111-139.

Raij, T., Uutela, K., \& Hari, R. (2000). Audiovisual integration of letters in the human brain. Neuron, 28, 617-625.

Raven, J., Raven, J. C., \& Court, J. H. (1998). Coloured progressive matrices. Oxford: Oxford Psychologists Press.

Schneider, W., \& Chein, J. M. (2003). Controlled \& automatic processing: Behavior, theory and biological mechanisms. Cognitive Science, 27, 525-559.

Schröger, E. (1998). Measurement and interpretation of the mismatch negativity. Behavior Research Methods, Instruments, \& Computers, 30, 131-145.

Semtlitsch, H., Anderer, P., Schuster, P., \& Presslich, O. (1986). A solution for reliable and valid reduction of ocular artefacts, applied to the P300 ERP. Psychophysiology, 23, 695-703.

Shafer, V. L., Morr, M. L., Kreuzer, J. A., \& Kurtzberg, D. (2000). Maturation of mismatch negativity in school-age children. Ear and Hearing, 21, 242-251.

Siegel, L. S., \& Faux, D. (1989). Acquisition of certain grapheme-phoneme correspondences in normally achieving and disabled readers. Reading and Writing, an Interdisciplinary Journal, 1, 37-52.

Snowling, M. J. (1980). The development of graphemephoneme correspondence in normal and dyslexic readers. Journal of Experimental Child Psychology, 29, 294-305.

Sowel, E. R., Peterson, B. S., Thompson, P. M., Welcome, S. E., Henkenius, A. L., \& Toga, A. W. (2003). Mapping cortical change across the human life span. Nature Neuroscience, 6, 309-315.

Van Atteveldt, N., Formisano, E., Blomert, L., \& Goebel, R. (2007). The effect of temporal asynchrony on the multisensory integration of letters and speech sounds. Cerebral Cortex, 13, 962-974.

Van Atteveldt, N., Formisano, E., Goebel, R., \& Blomert, L. (2004). Integration of letters and speech sounds in the human brain. Neuron, 43, 271-282.

Van den Bos, K. P., Lutje Spelberg, H. C., Scheepsma, A. J. M., \& De Vries, J. R. (1999). De Klepel: Pseudowoordentest. Lisse: Swets \& Zeitlinger. 
Van Wassenhove, V., Grant, K. W., \& Poeppel, D. (2007). Temporal window of integration in auditoryvisual speech perception. Neuropsychologia, 45, 598-607.

Vellutino, F. R., Fletcher, J. M., Snowling, M. J., \& Scanlon, D. M. (2004). Specific reading disability (dyslexia): What have we learned in the past four decades? Journal of Child Psychology and Psychiatry, 45, 2-40.

Wentink, H., \& Verhoeven, L. (2003). Protocol leesproblemen en dyslexie. Nijmegen: Expertisecentrum Nederlands.
Winkler, I., Kujala, A., Tiitinen, H., Sivonen, P., Alku, P., Lehtokoski, A., et al. (1999). Brain responses reveal the learning of foreign language phonemes. Psychophysiology, 36, 638-642.

Yabe, H., Asai, R., Hiruma, T., Sutoh, T., Koyama, S., Kakigi, R., et al. (2004). Sound perception affected by nonlinear variation of accuracy in memory trace. NeuroReport, 15, 2813-2817.

Yabe, H., Tervaniemi, M., Sinkkonen, J., Huotilainen, M., Ilmoniemi, R., \& Naatanen, R. (1998). Temporal window of integration of auditory information in the human brain. Psychophysiology, 35, 615-619. 